\title{
La palabra es mi reino ${ }^{93}$
}

Paul Ricœur ${ }^{94}$

C'est une véritable vie en commun qui naît autour de la communication du savoir, une vie sociétaire qui a ses règles, son esprit et son cour ; et l'homme tout entier s'y exerce... L'école est éducatrice parce qu'elle est enseignante, et non l'inverse.

¿Qué es lo que hago cuando enseño? Hablo. No tengo otra manera de ganarme el pan y tampoco tengo otra dignidad; no tengo otra manera de transformar el mundo y además no tengo otra manera de influenciar a los hombres. La palabra es mi trabajo; la palabra es mi reino.

Mis alumnos tendrán, en su mayoría, una relación diferente con las cosas y los hombres; ellos construirán algo con sus manos; o bien hablarán y escribirán en oficinas, almacenes, administraciones; pero su palabra no será una palabra que enseñe; será un fragmento de acción, una orden, un plan, un esbozo de acción. Mi palabra no inicia ninguna acción, no ordena ninguna acción que pueda caer directa o indirectamente en la producción; hablo solamente para comunicarle a la generación adolescente lo que sabe y lo que busca la generación adulta. Esta comunicación por la palabra de un saber adquirido y de una investigación en movimiento es mi razón de ser: mi oficio y mi honor. Nunca estaré celoso de los que "viven la vida" y que "tienen los pies sobre la

\footnotetext{
${ }^{93}(\mathrm{NdE})$ Este texto es la introducción de un articulo publicado por Paul Ricœur en la revista Esprit en 1955. El texto, a pesar de los años, continua vigente. El profesor Ricœur autorizó su reproducción en el sitio web Le Portique en 1999. El texto puede consultarse online : Paul Ricœur, "La parole est mon royaume ", Le Portique [En ligne], 4 | 1999, mis en ligne le 11 mars 2005. URL: http://leportique.revues.org/ index 263.html Se autoriza la reproducción y la traducción del documento siempre y cuando se cite la fuente. La versión española es del profesor Miguel Ángel Mahecha Bermúdez.

${ }^{44}$ (NdE) Paul Ricour (Valence, 27 de febrero de 1913. Châtenay-Malabry, 20 de mayo de 2005) fue un filósofo y antropólogo francés conocido por su intento de combinar la descripción fenomenológica con la interpretación hermenéutica. Algunas de sus obras conocidas, traducidas al español son: Si mismo como otro (1996), Tiempo y Narración (3 tomos, 1995-1996), Freud: una interpretación de la cultura (1999), La metáfora viva (2001) y Sobre la traducción (2005). En una nota necrológica, publicada en la revista Ideas y Valores 128, 1995, pp. 105-116, el profesor Luis Augusto Campos sintetiza uno de los rasgos más distintivos del filósofo: "Ricour se ha presentado siempre como un critico atento de su propia obra. Así, luego de la redacción de la monumental obra Si mismo como otro, él siente la necesidad de llenar una laguna que habia quedado en su reflexión sobre el tiempo y la narración, y que se refiere a un elemento que juega un papel de mediación entre estos dos: se trata de la memoria, y su correlato, el olvido. Aquí reaparecerán algunos temas abordados precedentemente, como son la culpabilidad, lo justo, así como aquel de una dificil, casi improbable pero sin embargo posible experiencia de reconciliación en el perdón. Esta será la problemática abordada en La memoria, la historia y el olvido, obra monumental que revela nuevamente la responsabilidad de este filósofo por su cuidado y su constancia en buscar y proponer nuevos elementos, quizá faitantes, que vendrian a completar su anhelada antropología." (p. 114)
} 
tierra", como lo afirman los profesores descontentos de si mismos. Mi realidad y mi vida es la empresa de las palabras, oraciones y discursos.

Puedo recorrer el vasto campo de las materias enseñadas: cada una de ellas crea una manera de hablar que la articula en sí misma, la expresa por sí misma y la anuncia para otro. Si enseño las matemáticas, me convierto, en el acto de enseñar, en la palabra que se agota en la denominación exacta, la oración reducida a la significación pura, el discurso constructor de la prueba, en resumen, la palabra sellada por la necesidad. Si enseño la poesía, me acerco, con los recursos de mi rosa, a un lenguaje que crea y recrea la substancia de las presencias y las correspondencias por la unión carnal del sentido y de la voz. Si enseño las ciencias naturales, soy el servidor de otro lenguaje, que des-cribe el mundo, que articula simultáneamente el hecho y la ley, que vehicula la objetividad de todos mis objetos y la universalidad de todos los enunciados sobre el mundo. Si soy historiador, entro en un discurso que nació del relato y que tiende hacia el rigor de una lengua capaz de transformar una huella en documento, de analizar y de ligar, de reconstruir y hacer revivir. Si enseño las lenguas vivas, estoy al servicio de la comunicación pura, más allá de la diferencia de las lenguas; lucho contra la diferencia, busco al otro hombre en su otra lengua y en la escritura de sus obras. Si enseño la filosofía, es entonces a la edificación de un discurso a lo que me consagro, de un discurso que no sea ya más sólo un símbolo como el del matemático, sino realidad; que no sea sólo poesía, sino verdad; que se a más hecho, sino condición de posibilidad; que no sea más relato, sino orden y razón.

La Universidad es el Universo de los poderes múltiples del lenguaje en el momento de la comunicación del "decir". En consecuencia sólo hay una cosa que una reforma de la Enseñanza no puede proponer alcanzar: ;el final del reino del habla en la enseñanza! Toda reforma es reforma al interior del lenguaje que una generación le habla a la otra para transmitirle los frutos y el movimiento de su cultura.

Tal es el núcleo de toda meditación prejuiciosa a una reforma de la enseñanza en general; el resto se construye sobre esta base; el resto: y en primer lugar todo lo que llamamos educación. Es una verdadera vida en común que nace alrededor de la comunicación del saber, una vida social que tiene sus reglas, su espíritu y su tcorazón; y el hombre en su totalidad se desempeña. Pero esta vida no es la vida en los oficios, en la ciudad, en el mundo; es una vida completa -o al menos la vida de la escuela debería ser una vida digna de este nombre-, pero esta vida está completamente regulada por la tarea mayor del habla y no por la eficiencia profesional. Es por eso que se excluye que una reforma de la enseñanza pueda proponer edificar la vida social de la clase, de la escuela, de la Universidad a la imagen de las relaciones humanas en la vida profesional; eta vida no puede ser una anticipación o una reproducción a escala reducida de la vida real, si se decide llamar vida real a la vida profesional, la inserción del hombre en la división social del trabajo; esta vida es la vida propia de una comunidad generada por la comunicación del saber de una generación a otra. La escuela es educadora porque es enseñante, y no lo inverso. 